\title{
O INFINITO NOS DISTÚRBIOS DO PROCESSO ENSINO/APRENDIZADO DE ALUNOS INGRESSANTES NOS CURSOS DE CIÊNCIAS EXATAS
}

\author{
Cleber Luiz da Cunha ${ }^{1}$, Adriano Rodrigues Ruiz ${ }^{2}$ \\ ${ }^{1}$ Discente do Curso de Mestrado em Educação da UNOESTE. ${ }^{2}$ Docente do Curso de Mestrado em Educação da \\ UNOESTE.
}

\section{RESUMO}

O presente estudo trata-se de uma pesquisa diagnóstica para verificar até que ponto os (pré) conceitos a cerca do infinito, trabalhados durante o Ensino Fundamental e Médio, influenciam no aprendizado dos alunos ingressantes de cursos de graduação na área de Ciências Exatas. 0 instrumento utilizado em tal verificação foi um questionário com perguntas abertas, focando conhecer as "imagens conceituais" dos alunos sobre o tema e sobre elas fazer inferências. Participaram da pesquisa alunos do segundo termo de Licenciatura em Matemática de uma faculdade de Presidente Prudente - SP, caracterizando um estudo de caso. Os resultados evidenciam as relações existentes entre os diversos tratamentos (conceito imagem) que são dados, pelos alunos ingressantes na graduação, ao tema e que dificuldades estas causam. Indicam a necessidade de um maior envolvimento com um assunto por parte dos professores tanto do Ensino Médio quanto da Graduação por meio de temas nos quais o infinito atual seja transparente, promovendo aos estudantes condições para que possam apropriar-se deste importante conceito e assim aspirarem ir além em seus conhecimentos matemáticos.

Palavras-chave: infinito, números Reais, conceito imagem, Cálculo Diferencial

\section{INTRODUÇÃO E OBJETIVO}

São inúmeros os problemas que o conceito de infinito coloca na educação matemática, quer em termos de aprendizagem e construção do conhecimento, quer em termos do desenvolvimento cognitivo. O conceito de infinito tem uma longa e dramática história na filosofia e na matemática e embora seja altamente significativo em matemática, inquestionável enquanto construção lógica, a sua realidade psicológica permanece inexplicável, complexa e contraditória. Para uns não compreendemos o infinito nem sensorialmente nem por imaginação, o conhecimento surge do conflito entre a finitude do mundo à nossa volta e o conhecimento da "possibilidade" do infinito. Mas se não houvesse o domínio do infinitamente pequeno por parte de Newton e Leibniz não teríamos o cálculo diferencial e não seríamos capazes de formular nem mesmo as leis físicas mais simples.

Os conteúdos ensinados no currículo escolar do Ensino Fundamental possuem objetivos, inicialmente, de uso imediato caracterizados pela identificação da matemática operacional presente no mundo que nos cerca e mais à frente, pelo desenvolvimento do raciocínio abstrato através da análise numérica, álgebra e geometria, formando a base conceitual fundamental para o 
Ensino Médio e para o Curso Superior. Neste último, o Cálculo Diferencial e Integral exige que a abstração vá mais além e as análises devem ser realizadas sobre problemas com resultados em geral não esperados. Durante este processo o aluno é levado a pensar nas diferenças existentes entre os diversos tipos de números e no condicionamento destes em conjuntos bem identificados por suas propriedades. As idéias de função, continuidade e limites se fazem presente quando os números Reais são apresentados.

O processo de construção do conjunto dos números Reais, assim como as propriedades do próprio conjunto em si, são temas importantes ao aluno que adentra a um curso na área de exatas e que tem estreita relação com seus (pré) conceitos de infinitude e cardinalidade trazidos do Ensino Médio. Mesmo que este aluno não tenha ainda uma visão teórica abrangente sobre os números reais, por outro lado possui uma experiência escolar de vários anos ao longo da qual construiu certas "imagens conceituais" (TALL e VINNER, 1981) - corretas ou não do ponto de vista da teoria matemática - que constituem o seu saber sobre este conjunto numérico. Ignorar estas imagens no processo de ensino e acreditar que serão abandonadas pelos alunos para serem substituídas de imediato pela definição formalmente correta apresentada pelo professor do curso superior pode levar a criação de obstáculos para a aprendizagem destes alunos. Em geral, o aluno tende a manter suas imagens conceituais e acrescentar a estas uma versão da definição formal que lhe é apresentada, construindo assim uma espécie de mosaico com as várias representações de um mesmo conceito onde, dependendo da circunstância em que um problema se apresenta, ele recorre a uma ou a outra dessas representações.

O curso de Cálculo Diferencial e Integral, considerado básico nos cursos de áreas de ciências exatas no Ensino Superior, tem mostrado em vários estudos um índice alto de abandono e repetência (MASETTO, 1992; NASCIMENTO, 1997 e MORELLATTI, 2001). As causas mais comumente apontadas são: as dificuldades intrínsecas da disciplina, a falta de base dos alunos e um grande distanciamento metodológico entre o Ensino Médio e o Ensino Superior (NASCIMENTO, 2000). Mesmo que estas e outras pesquisas venham demonstrando que a questão metodológica é de extrema importância nestes casos, ainda assim continuam indicando que a consolidação da base conceitual dos alunos é fator fundamental para o sucesso da aplicação de qualquer metodologia.

Pesquisas nacionais e internacionais (AMADEI, 2005; MONAGHAN e FISCHBEIN, 2001; IGLIORI, 1998) evidenciam que grande parte das muitas dificuldades vivenciadas pelos alunos na aprendizagem de limites e continuidade de funções não são frutos diretos no novo conhecimento 
apresentado, mas já vêm devido a confusão na classificação de números racionais e irracionais, do desconhecimento da propriedade da densidade do conjunto dos números reais, ou seja, questões estas que têm estreita relação com o conceito matemático de infinito.

Diante dos novos problemas matemáticos apresentados no início da vida universitária, os estudantes respondem às tarefas escolares utilizando seus "conceitos imagem" ou na intuição. Assim, podem contrariar as expectativas do professor que espera uma resposta baseada na definição formal. Então, para o processo de ensino e aprendizagem da matemática, em particular a das construções e representações formais exigidas a um ingressante num curso superior na área das ciências Exatas, é importante considerar como os alunos expressam e relacionam os seus (pré) conceitos.

Assim, o objetivo desta pesquisa não é o de provar conjecturas ou obter dados estatísticos pertinentes ao objeto pesquisado, mas sim o de conhecer as (pré) concepções e imagens trazidas por alunos do Ensino Médio para o ensino superior dos conceitos formais relacionados aos conjuntos numéricos e a compreensão do infinito. Isto é, procurar fatores geradores de dificuldades para a compreensão da noção de infinito provindos do Ensino Médio, dada a sua relevância na construção do conhecimento matemático e as implicações deste no processo do ensino e aprendizagem de Cálculo e Análise Matemática num curso de formação de professores de Matemática.

Busca-se por meio de entrevistas com alunos dos termos iniciais num curso de Licenciatura em Matemática, verificar se há elementos formadores das imagens conceituais destes alunos ingressantes que podem servir de obstáculo na aprendizagem com "novos" conceitos a eles apresentados no curso de Cálculo, como limites, continuidade de uma função, densidade do conjunto dos números reais, todos que implícita ou explicitamente tem relação com o modo com que eles lidam com o conceito de infinito.

\section{METODOLOGIA DA PESQUISA}

A pesquisa desenvolveu-se numa abordagem qualitativa por meio de um estudo de caso, representado pelos alunos do curso de Licenciatura em Matemática de uma faculdade da cidade de Presidente Prudente - SP. Como envolve seres humanos, o projeto foi submetido e aprovado pelo Comitê de Ética na Pesquisa da Unoeste.

A organização deste trabalho teve início com um levantamento bibliográfico de textos que tratassem o tema "infinito", em especial aqueles que enfocassem as dificuldades que envolvem o 
ensino e aprendizagem do conceito formal do infinito matemático e as relações entre estas dificuldades e o rendimento de alunos dos cursos da área de Ciências Exatas no contato com o Cálculo Diferencial e Integral.

Vários livros, artigos científicos, teses e periódicos foram consultados (ver referências bibliográficas) a procura não só de um embasamento teórico para a elaboração do trabalho, mas sobretudo para verificar o que já foi pesquisado dentro do contexto do infinito e da teoria de conjuntos de Cantor. Também procurou-se textos que relacionassem o infinito como obstáculo no ensino da matemática.

Esta fase também teve como objetivo a busca de objetos para a elaboração e ajuste das questões que fazem parte do questionário que fora aplicado a 36 alunos do 2 o termo do curso de Licenciatura em Matemática. O questionário possui 6 questões e foi aplicado individualmente aos alunos, durante horário de aula, com um tempo de 30 minutos para seu preenchimento. Nenhum material de consulta foi disponibilizado e foi pedido para que cada um respondesse aquilo que soubesse, como entendesse, sem se preocupar com formalismos matemáticos.

Todas as questões elaboradas foram abertas, como um "convite" para que as respostas sejam apresentadas numa linguagem informal e espontânea, focando melhor conhecer as "imagens conceituais" dos alunos sobre o tema. Cada questão norteou a inferência dos conceitos imagem e definição dos investigados.

\section{RESULTADOS, DISCUSSÃO E CONCLUSÃO}

Os resultados evidenciam as relações existentes entre os diversos tratamentos que são dados, pelos alunos ingressantes na graduação, ao tema, suas imagens conceituais e que dificuldades estas causam durante o desenvolvimento de disciplinas como o Cálculo Diferencial.

Além das dificuldades demonstradas pelos participantes da pesquisa, deparei-me com minhas próprias dificuldades à medida que me aprofundei nos diversos aspectos do tema. Estes fatos me fazem constatar que há a necessidade de um maior envolvimento com um assunto em que poucos professores se preocupam em desenvolver durante o Ensino Médio e que parece continuar assim nos cursos de Cálculo, sendo uma causa de entrave no ensino dessa disciplina.

O conflito entre a intuição e o conceito científico é evidente e desafiador para os envolvidos no processo do ensino e aprendizagem da matemática, em particular na noção de infinito atual, sendo motivo para que as dificuldades na aprendizagem, advindas deste conflito, sejam persistentes e de difícil trato no desenrolar da graduação. 
Os dois infinitos, o potencial de Aristóteles e o atual de Cantor, é assunto importante que não consta nos livros didáticos do Ensino Fundamental e Médio e tal ausência é um dos fatores que contribuem para a falta de expressão dos alunos pesquisados. A noção de infinito, que desde o inicio dos tempos é motivo de dificuldade constante na construção do saber da Matemática, deve ser um dos objetivos distintos dos educadores desta área do conhecimento. A essência abstrata do infinito matemático e tudo que o cerca, mais sua fundamental participação na constituição de conceitos como dos conjuntos numéricos e de limites, mais que justificam esta atitude.

Dentre as maiores dificuldades demonstradas pelos participantes destacamos:

- a de que duas grandezas são sempre comensuráveis;

- a não distinção da cardinalidade dos naturais e a dos reais;

- confusão entre o número e grandeza, atribuindo o mesmo significado a ambos através de uma aproximação;

- desconhecimento da propriedade da densidade do conjunto dos Racionais nos Reais, assim como o desta propriedade no modelo da reta real;

- não reconhecimento de quando um determinado subconjunto limitado dos Reais possui elemento máximo ou elemento mínimo.

Os itens aqui citados são detalhes importantes que muitas vezes impedem o aluno recém iniciado em Cálculo de compreender e realmente formar um conceito sólido sobre as bases que sustentam a disciplina.

Nas relações entre os conjuntos é preciso enfatizar uma visão global destes conjuntos para além da relação de inclusão, demonstrando verdadeiramente como um se situa dentro do outro, as propriedades gerais numa visão mais ampla e as específicas do conjunto mais restrito.

É importante ressaltar que os alunos muitas vezes fazem uso de critérios (imagens conceituais) contraditórios ao mesmo tempo, na busca de resposta, sem mesmo perceberem ou demonstrar qualquer desconforto com esta prática.

Fica claro que o infinito matemático está longe de ser um objeto do conhecimento que as pessoas aceitem facilmente a partir de sua interação com o ambiente físico. $\mathrm{O}$ conceito de infinito não pode ser solidificado por si só porque todas as coisas que existem são finitas e, portanto, apresentam um fim ou uma delimitação. Assim, este conceito de infinito vem da noção de negação daquilo que é finito. 
Para que o infinito se transforme em algo acerca da qual os alunos tenham a capacidade de pensar e operar, faz-se necessária a intervenção de processos complexos de representação, que por sua vez requerem a participação em textos educativos que propiciem um alto grau de reflexão matemática.

É imperativo trabalhar com temas onde o infinito atual seja transparente ou este pode se converter em um sério obstáculo para favorecer a compreensão deste conceito matemático indispensável para o egresso da matemática na faculdade. Para promover aos estudantes, condições para que possam apropriar-se deste importante conceito e assim aspirarem ir além em seus pensamentos matemáticos, é indispensável que professores de matemática nos anos de formação do aluno, principalmente no Ensino Médio e inicio do curso superior, revejam suas metas e dêem atenção a textos educacionais que coloquem de maneira explícita noções que pertençam ao infinito matemático.

\section{REFERÊNCIAS}

AMADEI, Flávio Luiz. O Infinito: um obstáculo no estudo da matemática. São Paulo, PUC-SP, 2005. Dissertação em Mestrado em Educação Matemática.

DIAS, Marisa da Silva. Reta Real: conceito imagem e conceito definição. São Paulo, PUC-SP, 2002. Dissertação em Mestrado em Educação Matemática.

FISCHBEIN, Efrain. Tacit model and infinity. Educational Studies in Mathematics (International Journal). V.48, n. 2 e 3, 2001.

IGLIORI, Sonia B. C. e SILVA, Benedito A. Conhecimento de concepções prévias dos estudantes sobre números reais: um suporte para a melhoria do ensino-aprendizagem. 21aㅡ Reunião Anual da ANPED, 1998.

MONAGHAN, John. Young people's ideas of infinity. Educational Studies in Mathematics (International Journal). V. 48, n. 2 e 3, 2001.

NASCIMENTO, J. L. do. A recuperação dos Pré-Conceitos do Cálculo, XXVII COBENGE, Ouro Preto, pp 1472-1478, 2000.

NASCIMENTO, J. L. do. A reprovação em Cálculo I: Investigação de Causas, Rio de Janeiro, Monografia de Licenciatura - UFRJ, 1997.

TALL, D.; VINNER,S. Concept image and a concept definition in Mathematics with particular to limits and continuity. Educational Studies in Mathematics, vol. 12, pp151-169, 1981. http://dx.doi.org/10.1007/BF00305619 